\title{
First Report of Lilac ring mottle virus Infecting Lilac in the United States
}

\begin{abstract}
Dipak Sharma-Poudyal and Nancy K. Osterbauer, Oregon Department of Agriculture, Salem 97301; Melodie L. Putnam, Oregon State University Plant Clinic, Corvallis 97331; and Simon W. Scott, Clemson University, Clemson, SC 29634
\end{abstract}

Accepted for publication 26 May 2016. Published 14 July 2016.

Sharma-Poudyal, D., Osterbauer, N. K., Putnam, M. L., and Scott, S. W. 2016. First report of Lilac ring mottle virus infecting lilac in the United States. Plant Health Prog. 17:158-159.

In May 2015, the Oregon Department of Agriculture investigated a report of potential virus symptoms being observed on lilac plants (Syringa vulgaris L.) produced by a nursery in Marion County. Simultaneously, symptomatic lilac plant samples were received by the Oregon State University Plant Clinic from a customer of the same nursery. Lilac 'President Grevy' plants inspected at the nursery showed symptoms of leaf deformation, reduction in leaf size, ring spots, and line patterns (Fig. 1). Two months later, similar foliar symptoms were observed on lilac 'Krasavitsa Moskvy' plants at the same nursery (Fig. 2). Symptoms on both cultivars resembled those reported for Lilac ring mottle virus (LiRMoV) (Van Der Meer et al. 1976). LiRMoV is an isometric RNA virus within the family Bromoviridae and genus Ilarvirus (Scott and Ge 1995; Scott and Zimmerman 2008) and has only been reported from the Netherlands. The virus was sap transmissible to herbaceous hosts under experimental conditions and was seed transmissible in the experimental hosts Chenopodium quinoa, C. amaranticolor, and Celosia argentea (Van der Meer et al. 1976). Symptom expression in infected lilac is influenced by environmental conditions and may be erratic; thus, infections may remain cryptic for years (Van der Meer et al. 1976).

To determine if LiRMoV was present in the symptomatic lilacs, total nucleic acids (TNA) were extracted from symptomatic leaf tissues using a procedure modified from Hughes and Galau (1988). The TNA was used in ONE-STEP PCR reactions

(Qiagen, Germantown, MD) at a melting temperature of $55^{\circ} \mathrm{C}$ and with primers (downstream: 5'-GAGACCGAAGTCTTCTTCC-3' and upstream: 5'-CCACGTGCTTCTCACCC-3') specific for the movement protein of the RNA3 of LiRMoV (GenBank Accession No. U17391) (Scott and Zimmerman 2008). In addition to the TNA from the samples, a positive control (plasmid pLRMV-7) (Scott and Zimmerman 2008) and negative controls (healthy plant tissue and water) were analyzed in concurrent PCR reactions. The anticipated 649-bp amplicon was produced in the lilac samples and in the positive control, but not in the negative controls. The amplicons from seven lilac samples were cloned using the pGemT Easy Vector (Promega, Madison, WI), selected by blue-white screening, and then sequenced using the primer M13F. The contiguous sequence generated was deposited into GenBank (Accession No. KX090269). Six of the seven clones contained an

Corresponding author: N K. Osterbauer. Email: nosterbauer@oda.state.or.us.

doi:10.1094/PHP-BR-15-0055

(C) 2016 The American Phytopathological Society

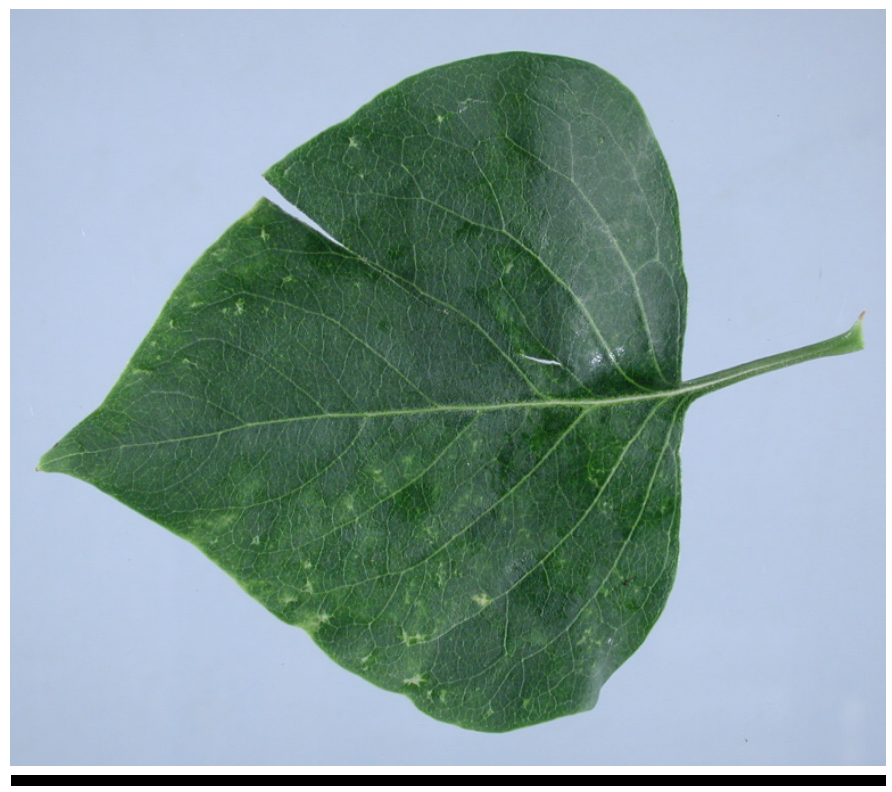

FIGURE 1

Foliar symptoms caused by Lilac ring mottle virus on lilac 'President Grevy.'

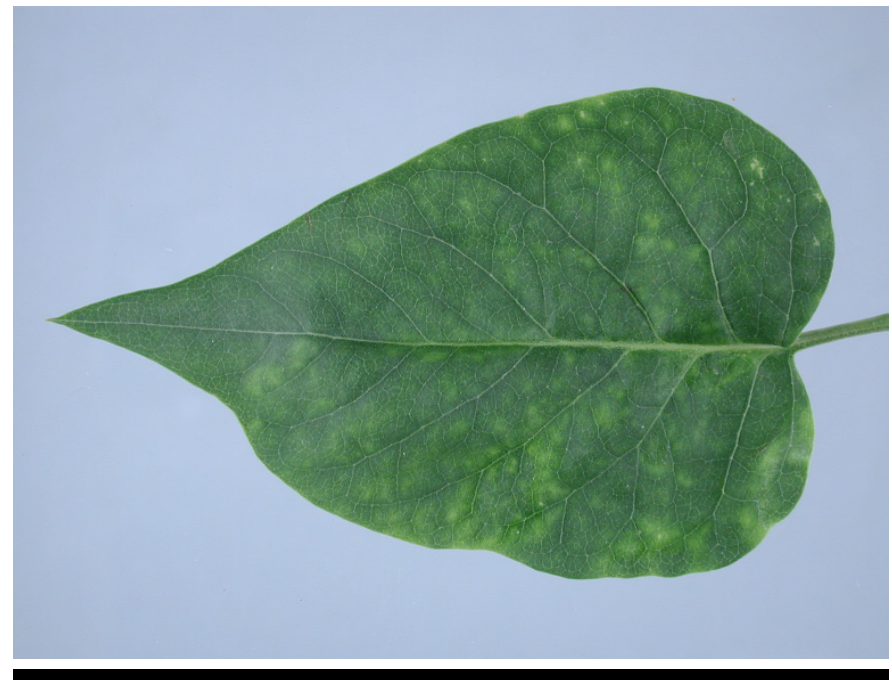

FIGURE 2

Foliar symptoms caused by Lilac ring mottle virus on lilac 'Krasavitsa Moskvy.' 
insert that showed $>99 \%$ homology with the published sequence for the RNA3 of LiRMoV (GenBank Accession No. U17391).

Tomato mosaic virus (ToMV), Arabis mosaic virus (ArMV), and Lilac leaf chlorosis virus (LLVC) have also been described as infecting lilac (Cooper 1993). Additional PCR testing of the lilac samples' TNA for these three viruses was completed. Amplicons were produced from the lilac samples of the appropriate sizes for LLCV (271 bp) (James et al. 2010) and for ToMV (318 bp, using the primers $1180,5^{\prime}$-CGAGAGGGGCAACAAACAT-3', and 1181, 5'-ACCTGTCTCCATCTCTTTGG-3' [S. Scott unpublished]); ArMV was not detected. Identity of the amplicons produced was confirmed by sequencing.

Samples received by the OSU Plant Clinic were examined using transmission electron microscopy (TEM) at the OSU Electron Microscopy Facility, which used two methods to examine symptomatic leaves. In the first, the leaf tissue was cut into $1-\mathrm{mm}$ strips and put in fixative (2.5\% glutaraldehyde plus $1 \%$ paraformaldehyde in sodium cacodylate buffer, $0.1 \mathrm{M}$ at $7.4 \mathrm{pH}$ ) overnight. The following day the tissue was crushed to express sap, which was collected on a copper grid, stained with $2 \%$ aqueous ammonium phosphotungstic acid, and examined. The second method was a simple expression of sap from unfixed tissue, which was then stained with $2 \%$ uranyl acetate in 50\% ethanol. Both preparations were examined using a FEI Titan 80200 TEM/STEM electron microscope. No virus particles were observed in either preparation.

This is the first report of LiRMoV from lilac cultivars President Grevy and Krasavitsa Moskvy in the United States. These cultivars were introduced into North America before 1950 and are grown in landscapes in 31 states and four Canadian provinces (Favorite 2006). LLCV was recently detected and described from Canada (James et al. 2010) and ToMV has previously been reported infecting a lilac hybrid in New York (Castello et al.
1992). Fruit trees infected by Ilarvirus and other viruses often exhibit an acute phase, which occurs when the plant is initially infected and symptoms are obvious, and a chronic phase, which occurs in subsequent growing seasons when systemic infection has been established and plants may appear asymptomatic (Nemeth 1986). It is possible LiRMoV, ToMV, and LLCV have been present in these cultivars for many years as cryptic infections. The infected plants at the Marion County nursery were destroyed.

\section{LITERATURE CITED}

Castello, J. D., Hibben, C. R., and Jacobi, V. 1992. Isolation of tomato mosaic virus from lilac. Plant Dis. 76:696-699.

Cooper, J. I. 1993. Virus Diseases of Trees and Shrubs, 2nd ed. Chapman and Hall, London.

Favorite, J. 2006. Lilac: Syringa vulgaris. USDA Natural Resource Conservation Plant Guide, Washington, DC. http://plants.usda.gov/core/ profile?symbol=SYVU.

Hughes, D. W., and Galau, G. 1988. Preparation of RNA from cotton leaves and pollen. Plant Mol. Biol. Rep. 6:253-257.

James, D., Varga, A., Leippi, L., Godkin, S., and Masters, C. 2010. Sequence analysis of RNA2 and RNA3 of lilac leaf chlorosis virus: A putative new member of the genus Ilarvirus. Arch. Virol. 155:993-998.

Nemeth, M. 1986. Virus, Mycoplasma, and Rickettsia Diseases of Fruit Trees. Martinus Nijhoff, Dordrecht, Netherlands.

Scott, S. W., and Ge, X. 1995. The complete nucleotide sequence of the RNA 3 of lilac ring mottle ilarvirus. J. Gen. Virol. 76:1801-1806.

Scott, S. W., and Zimmerman, M. T. 2008. Partial nucleotide sequences of the RNA 1 and RNA2 of lilac ring mottle virus confirm that this virus should be considered a member of subgroup 2 of the genus Ilarvirus. Arch. Virol. 153:2169-2172.

Van Der Meer, F. A., Huttinga, H., and Maat, D. Z. 1976. Lilac ring mottle virus: Isolation from lilac, some properties, and relation to lilac ringspot disease. Neth. J. Plant Pathol. 82:67-80. 